\title{
NATURAL CONVECTIVE HEAT TRANSFER FROM A THIN TWO-SIDED HORIZONTAL ISOTHERMAL CIRCULAR PLATE WITH A CIRCULAR HOLE IN THE CENTER
}

\author{
Patrick H. Oosthuizen* \\ Queen's University, Kingston, ON, Canada K7L 3N6
}

\begin{abstract}
The natural convective heat transfer rate from a thin, horizontal, two-sided circular plate might be increased by having a small hole in the center of the plate and this has been investigated in the present numerical study. It has been assumed that the upper and lower plate surfaces are isothermal and at the same temperature, and that the flow is axisymmetric about the vertical center-line through the plate. The Boussinesq approach has been adopted. The solution has been obtained using ANSYS FLUENT ${ }^{\mathcal{O}}$. The mean heat transfer rates from the top and bottom plate surfaces and the total heat transfer rate from the entire heated surface have been expressed in terms of Nusselt numbers based on the effective plate diameter. These Nusselt numbers are dependent on the Rayleigh number based on the effective diameter of the plate, the ratio of the diameter of the hole in the center of the plate to the outer diameter of the plate, and on the Prandtl number, results being obtained for a Prandtl number of 0.74 . Heat transfer rate for a plate having a hole in its center has been compared with the heat transfer rate existing under the same conditions for a plate without a hole. The results show that there is some increase in the heat transfer rate in certain situations resulting from the presence of the center hole. This increase is generally relatively small. The results also show that in other situations the heat transfer rate decreases due to the center hole.
\end{abstract}

KEY WORDS: Natural convection, Numerical, Horizontal, Circular plate, Center hole, Heat transfer enhancement

\section{INTRODUCTION}

Natural convective heat transfer from two-sided horizontal plates occurs in some situations that arise in practice. Means of increasing the heat transfer rates in such situations have been discussed. It has been suggested that one possible means of accomplishing this is to incorporate a relatively small hole in the middle of the plate, the heat transfer increase then being the result of the changes in the flow pattern over the plate that are produced by the presence of the center hole. This possibility has been investigated in the present numerical study. A thin, horizontal, two-sided, circular, isothermal plate has been considered, the plate, in general, having a relatively small-diameter hole at its center. The configuration considered is shown in Fig. 1. The top and bottom surfaces of the plate are assumed to be at the same temperature which is higher than that of the surrounding fluid.

There have been some limited previous numerical and experimental studies of natural convective heat transfer from two-sided (top and bottom) thin horizontal plates, e.g., see [1-14]. None of these studies have dealt with the case of a circular plate with a hole in the center. The present study is part of a broad series of ongoing investigations of heat transfer from horizontal and near horizontal heated surfaces (see [15-27]).

*Corresponding Author: patrick.oosthuizen@queensu.ca 


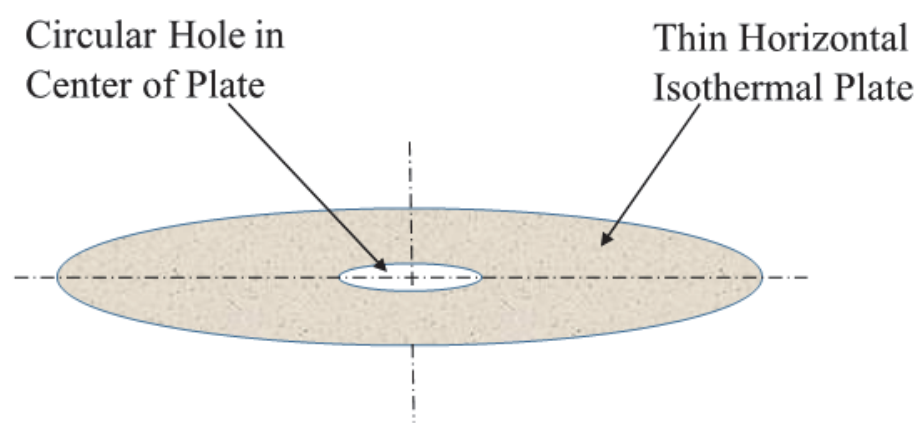

Fig. 1 Flow situation considered.

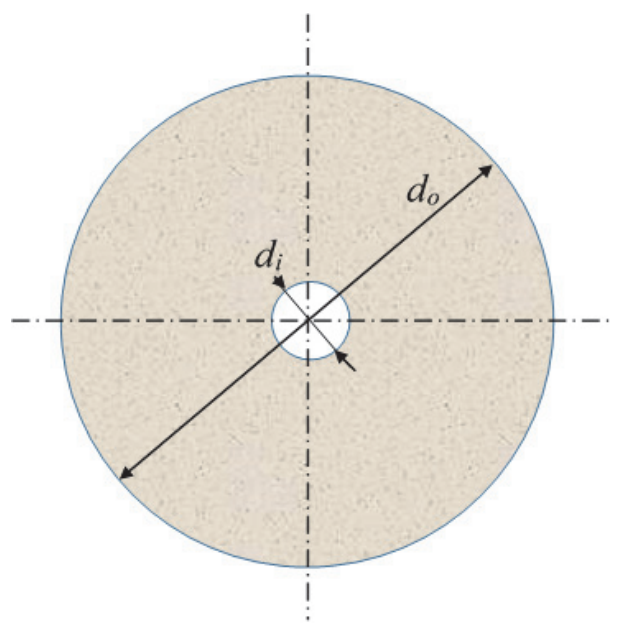

Fig. 2 Geometrical dimensions used in defining situation considered.

\section{SOLUTION PROCEDURE}

It has been assumed that the flow is steady and axisymmetric about the vertical center-line through the plate. The Boussinesq approach has been adopted in dealing with the buoyancy forces. The numerical solution has been obtained using the commercial CFD solver ANSYS FLUENT ${ }^{\circ}$. Extensive grid-independence and convergence criteria testing has been undertaken. The numerical approach adopted here in order to determine when turbulence develops involved solving the Reynolds averaged governing equations together with the turbulence model for all conditions considered and then monitoring the results obtained with increasing Rayleigh numbers to determine when significant turbulence effects develop. This approach has been used quite extensively in previous studies, e.g., see [28-34]. The $k$-epsilon turbulence model has been used. While this does not give good predictions of transition in all situations, the results obtained in previous studies indicate that the model does appear to give results of acceptable accuracy for the type of flow situation being considered here.

\section{RESULTS}

The aim of this study is to determine the effect of the center-hole on the heat transfer rate from the plate. Therefore, the heat transfer rate from a circular two-sided plate without a center-hole that has a diameter $d_{\mathrm{n}}$ has been compared with the heat transfer rate from a circular two-sided plate with a hole in the middle that has the same surface area as that of the plate without a center hole. Thus, if the diameter of the hole in the plate is $d_{\mathrm{i}}$ and the outer diameter of the plate with a center-hole is $d_{0}$ (see Fig. 2) then:

$$
\frac{\pi}{4} d_{n}^{2}=\frac{\pi}{4} d_{o}^{2}-\frac{\pi}{4} d_{i}^{2} \quad \text {,i.e., } \quad d_{n}^{2}=d_{o}^{2}-d_{i}^{2} \quad \text {,i.e., } \quad 1=D_{o}^{2}-D_{i}^{2}
$$


where $D_{\mathrm{o}}=d_{\mathrm{o}} / d_{\mathrm{n}}$ and $D_{\mathrm{i}}=d_{\mathrm{i}} / d_{\mathrm{n}}$

The heat transfer rates from the heated plate have been expressed in terms of a Nusselt number based on the diameter of the comparable circular plate that has no center hole, i.e., on $d_{n}$ and the difference between the plate temperature and the air temperature far from the plate. In the present study, attention has been given to the mean heat transfer rate from the upper surface of the plate, to the mean heat transfer rate from the lower surface of the plate, and to the total mean heat transfer rate from the upper and lower surfaces of the plate. These heat transfer rates from the heated plate has been expressed in terms of a Nusselt numbers based on $d_{n}$, the outside diameter of the equivalent plate with no central hole, and on the difference between the temperature of the heated plate and the fluid temperature far from the plate, i.e., the following Nusselt numbers have be used:

$$
N u_{\text {top }}=\frac{q_{\text {top }}^{\prime} l}{\left(T_{w}-T_{f}\right) k} \quad, \quad N u_{\text {bot }}=\frac{q_{\text {bot }}^{\prime} l}{\left(T_{w}-T_{f}\right) k} \quad, \quad N u=\frac{q_{\text {mean }}^{\prime} l}{\left(T_{w}-T_{f}\right) k}
$$

where $N u_{t o p}$ is the mean Nusselt number for the top surface of the plate, $N u_{b o t}$ is the mean Nusselt number for the bottom surface of the plate, and $N u$ is the mean Nusselt number based on the mean heat flux averaged over the top and bottom surfaces of the plate. The values of these Nusselt numbers will depend on:

1. the Rayleigh number, also based on the diameter the comparable circular plate that has no center hole and on the difference between the plate temperature and the air temperature far from the plate, i.e.:

$$
R a=\frac{\beta g d_{n}^{3}\left(T_{w}-T_{f}\right)}{v \alpha}
$$

2. the ratio of the inner hole diameter to the outer diameter of the plate, i.e., $D_{i}=d_{i} / d_{0}$.

3. the Prandtl number, Pr.

Results have only been obtained for a Prandtl number of 0.74 , i.e., effectively the value for air at ambient conditions. Hence the Nusselt numbers depend on $R a$ and $D_{i}$.

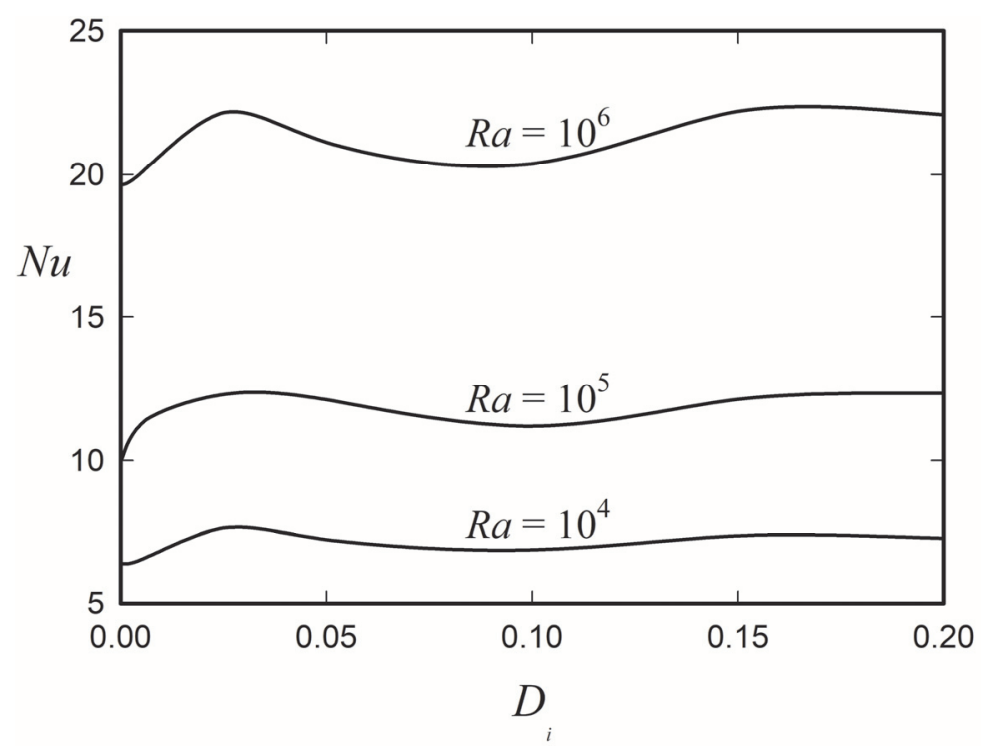

Fig. 3 Variation of the total mean Nusselt number with dimensionless hole diameter for lower Rayleigh numbers considered. 
Typical variations of the mean Nusselt number averaged over both the upper and lower heated surfaces of the plate with the dimensionless hole diameter, $D_{i}$, for various values of the Rayleigh number are shown in Figs. 3 to 5. Figure 3 gives results for lower values of the Rayleigh number considered, Figure 4 gives results for intermediate values of the Rayleigh number considered, and Figure 5 gives results for higher values of the Rayleigh number considered.

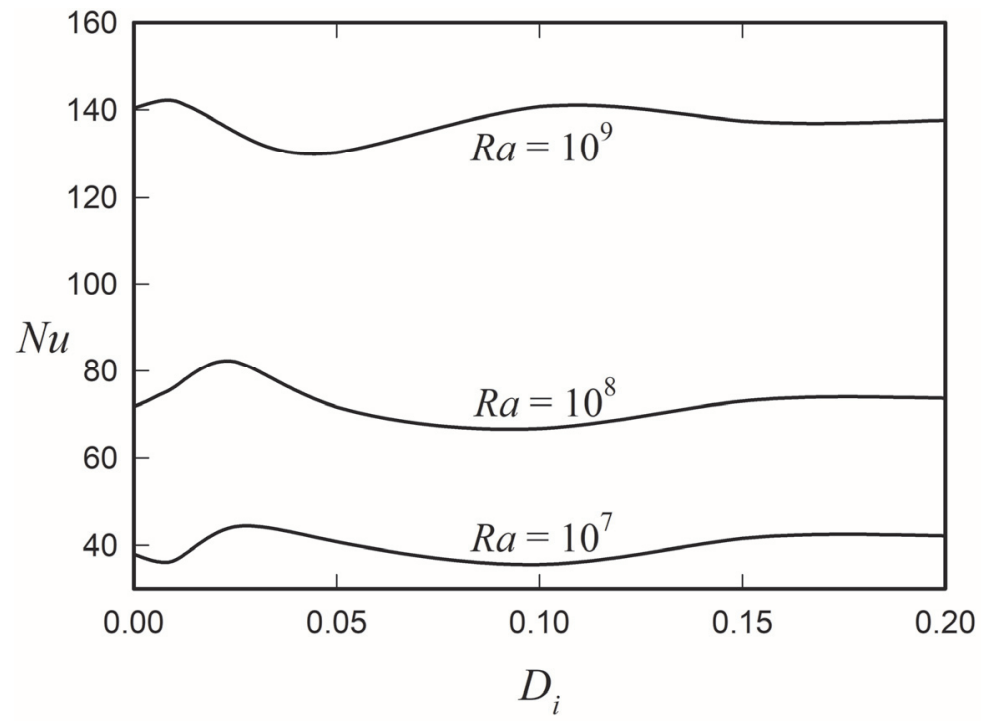

Fig. 4 Variation of the total mean Nusselt number with dimensionless hole diameter for intermediate Rayleigh numbers considered.

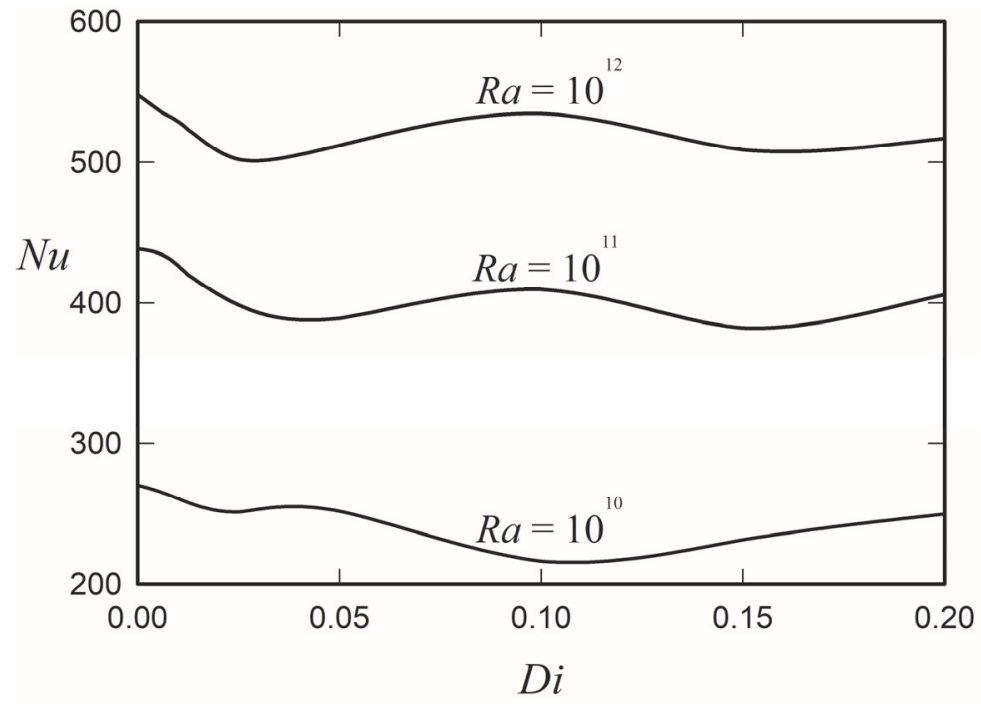

Fig. 5 Variation of the total mean Nusselt number with dimensionless hole diameter for higher Rayleigh numbers considered.

It will be seen from these results that, under some circumstances, the presence of the center hole does produce an increase in the Nusselt number relative to that existing at the same Rayleigh number when there is no center hole. However, this increase is relatively small and in some circumstances the presence of the center hole produces a decrease in the Nusselt number relative to that existing at the same Rayleigh number when there is no 
center hole. These changes in the effects of the center hole dimensionless diameter on the Nusselt number are more clearly shown by the results presented in Figs. 6 to 9. These figures show variations of the mean Nusselt number averaged over both the upper and lower heated surfaces of the plate with Rayleigh number for various dimensionless hole diameters. Also shown in each of these figures is the variation of the mean Nusselt number averaged over both the upper and lower heated surfaces of the plate with Rayleigh number for the case where there is no center hole. It will be seen from these figures that at the lower Rayleigh number values considered the presence of the center hole produces an increase in the Nusselt number relative to that existing at the same Rayleigh number when there is no center hole whereas at the higher Rayleigh number values considered the presence of the center hole produces a decrease in the Nusselt number relative to that existing at the same Rayleigh number when there is no center hole.

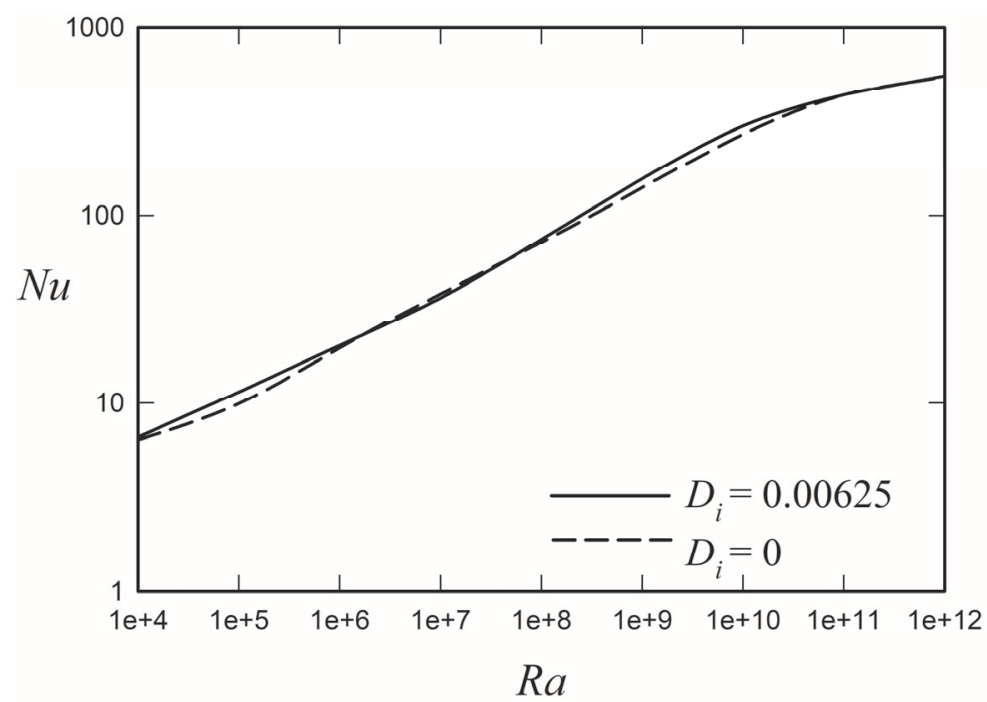

Fig. 6 Variation of the total mean Nusselt number with Rayleigh number for the case of a dimensionless hole diameter of 0.00625 and for the case without a hole in the plate.

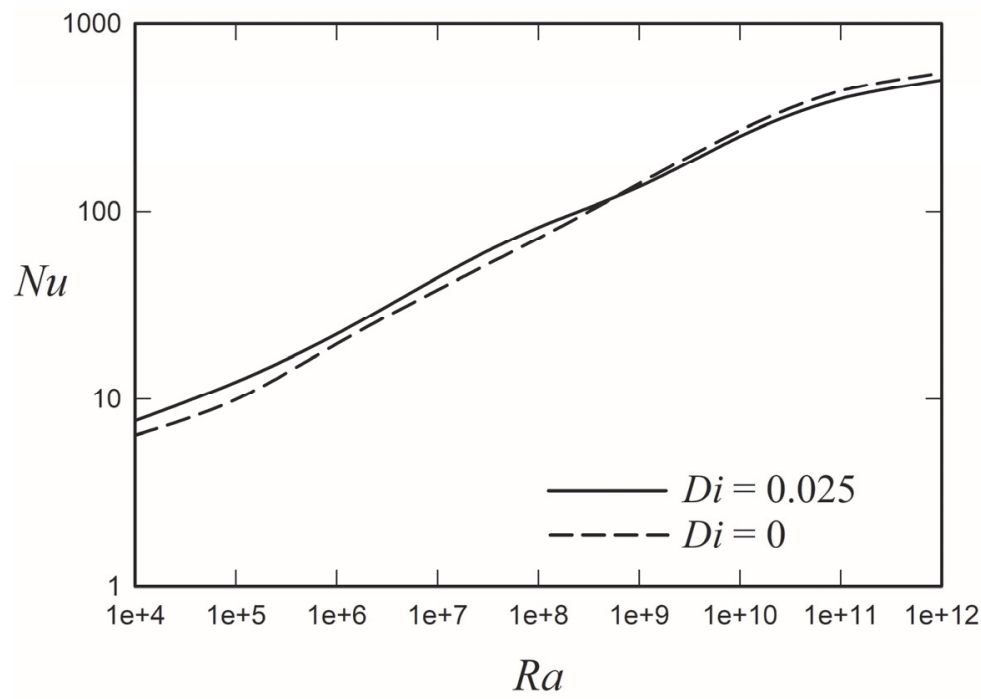

Fig. 7 Variation of the total mean Nusselt number with Rayleigh number for the case of a dimensionless hole diameter of 0.025 and for the case without a hole in the plate. 


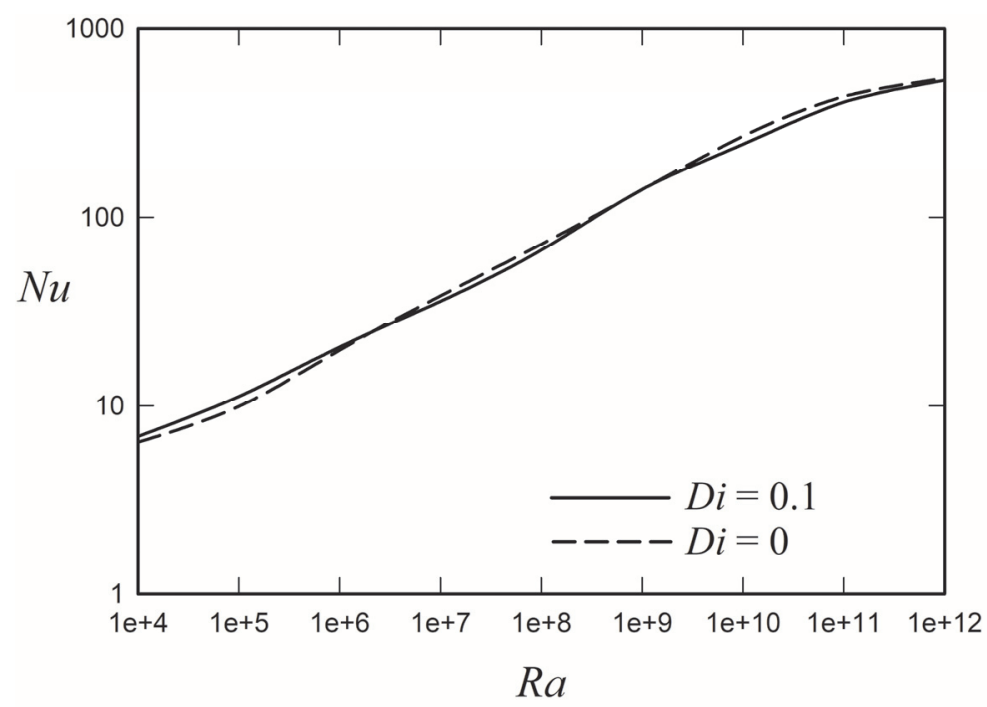

Fig. 8 Variation of the total mean Nusselt number with Rayleigh number for the case of a dimensionless hole diameter of 0.1 and for the case without a hole in the plate.

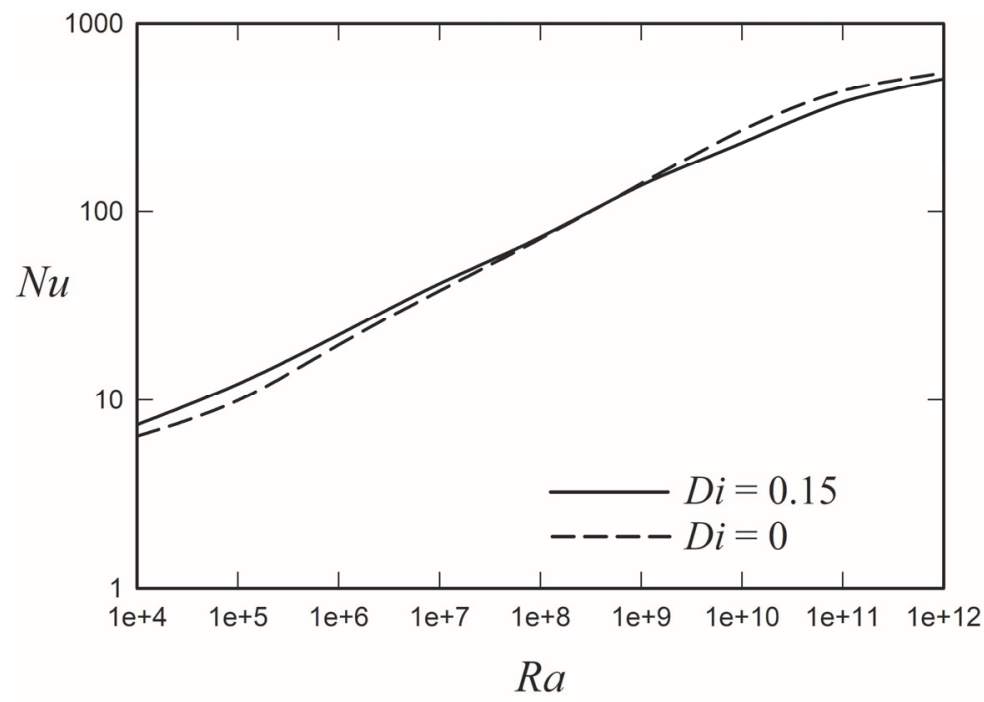

Fig. 9 Variation of the total mean Nusselt number with Rayleigh number for the case of a dimensionless hole diameter of 0.15 and for the case without a hole in the plate.

The results discussed above only considered the mean Nusselt number averaged over both the upper and lower heated surfaces of the plate $(\mathrm{Nu})$. In some situations, however, there is also an interest in the mean Nusselt number averaged over just the top (upper) surface of the plate $\left(N u_{t o p}\right)$ and in the mean Nusselt number averaged over just the bottom (lower) surface of the plate $\left(N u_{b o t}\right)$. Since the interest here is in the effect of the center hole on the Nusselt number values, variations of the ratios of these three Nusselt numbers to the corresponding values that would exist under the same conditions for a plate with no center hole with Rayleigh number are shown in Figs. 10 to 15 , each of these figures considering a different dimensionless hole diameter. It will be seen from the results given in these figures that, particularly at the higher Rayleigh numbers considered, the Nusselt number ratio for the bottom surface is higher than that for the top. 
TFEC-2020-32193

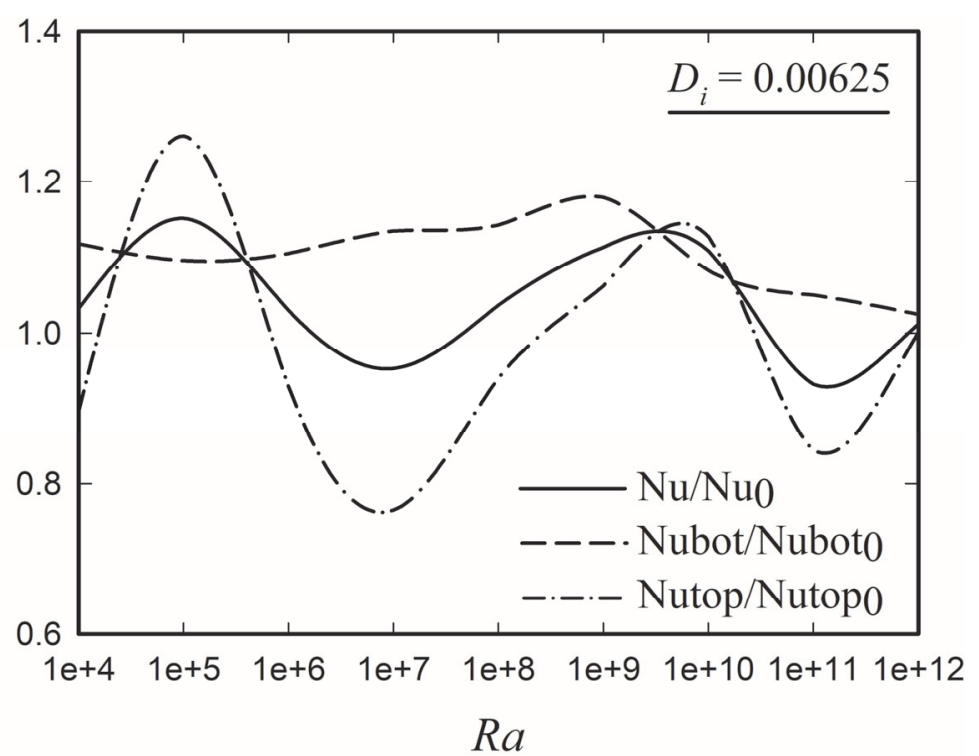

Fig. 10 Variation of the ratios of the total mean Nusselt number, the bottom surface mean Nusselt number, and the top surface mean Nusselt number to the values of the corresponding Nusselt numbers that exist under the same conditions when there is no hole in the plate with Rayleigh number for the case of a dimensionless hole diameter of 0.00625 .

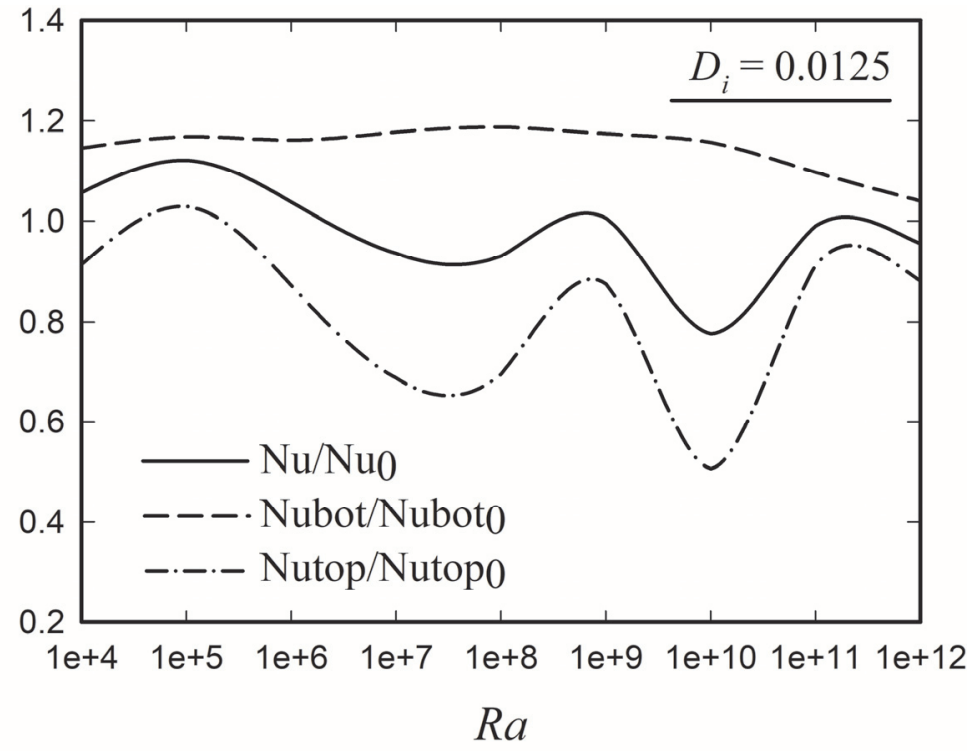

Fig. 11 Variations of the ratios of the total mean Nusselt number, the bottom surface mean Nusselt number, and the top surface mean Nusselt number to the values of the corresponding Nusselt numbers that exist under the same conditions without a hole in the plate with Rayleigh number for the case of a dimensionless hole diameter of 0.0125 . 
TFEC-2020-32193

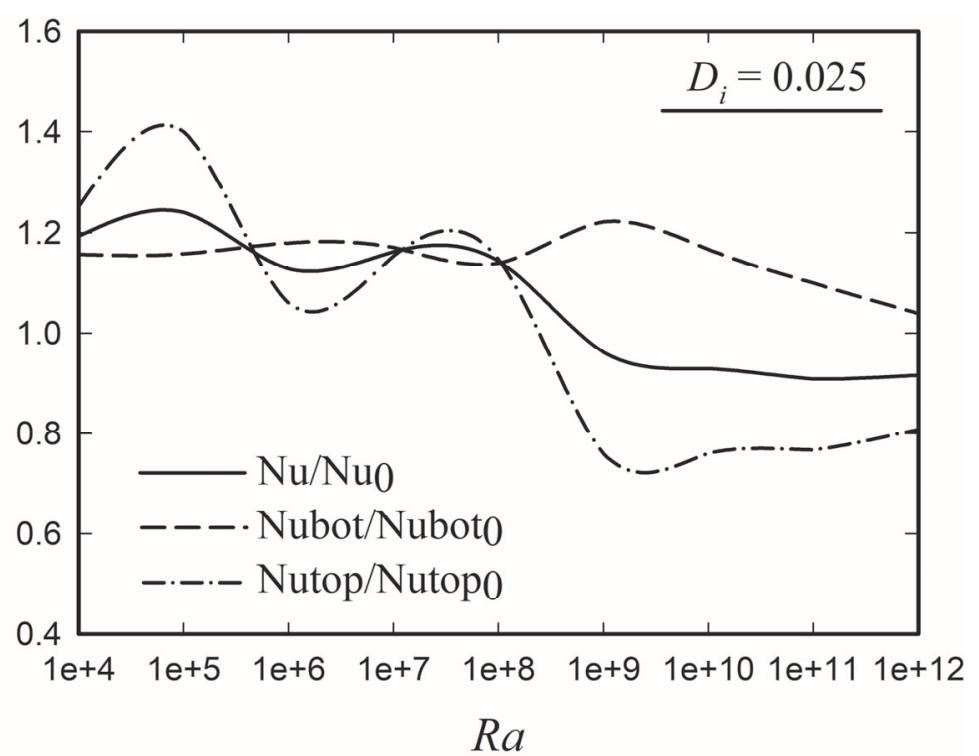

Fig. 12 Variations of the ratios of the total mean Nusselt number, the bottom surface mean Nusselt number, and the top surface mean Nusselt number to the values of the corresponding Nusselt numbers that exist under the same conditions without a hole in the plate with Rayleigh number for the case of a dimensionless hole diameter of 0.025 .

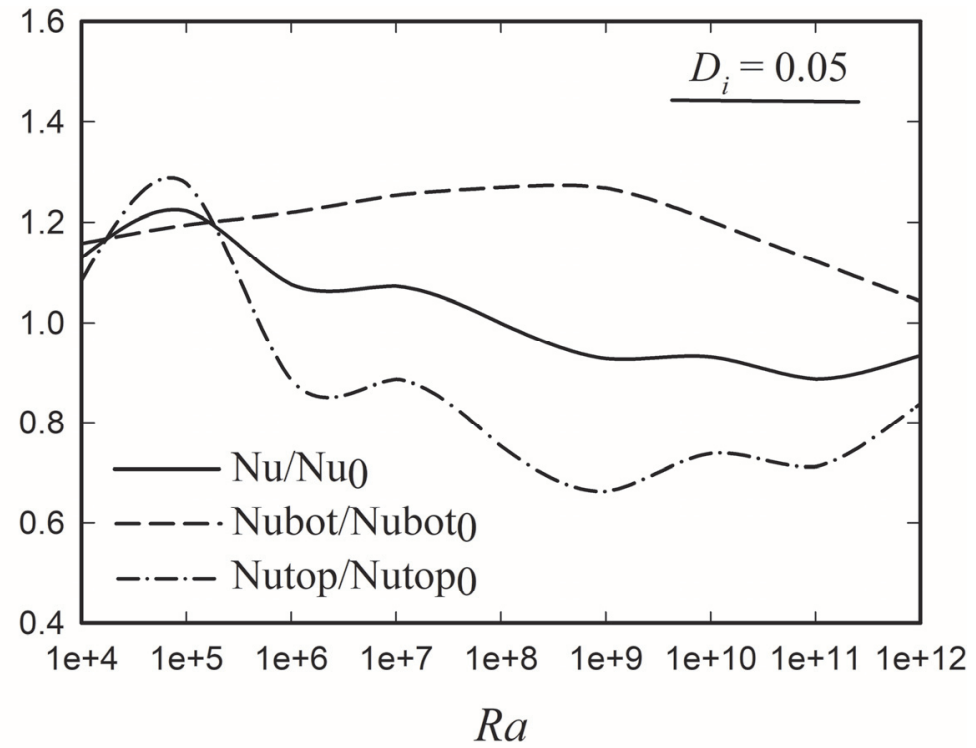

Fig. 13 Variations of the ratios of the total mean Nusselt number, the bottom surface mean Nusselt number, and the top surface mean Nusselt number to the values of the corresponding Nusselt numbers that exist under the same conditions without a hole in the plate with Rayleigh number for the case of a dimensionless hole diameter of 0.05 . 
TFEC-2020-32193

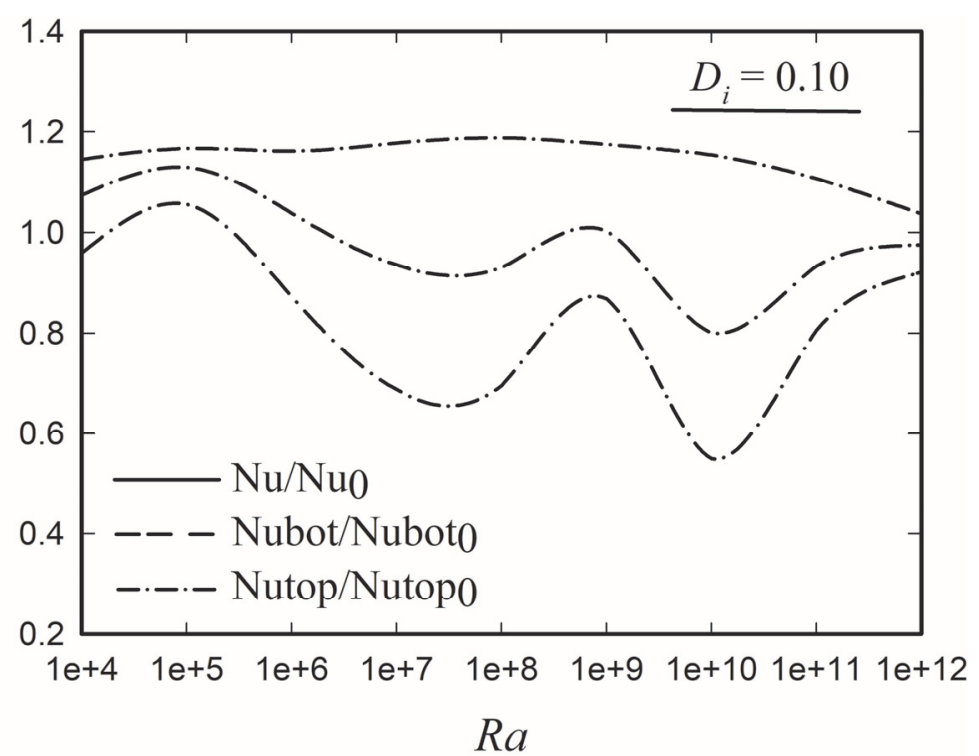

Fig. 14 Variations of the ratios of the total mean Nusselt number, the bottom surface mean Nusselt number, and the top surface mean Nusselt number to the values of the corresponding Nusselt numbers that exist under the same conditions without a hole in the plate with Rayleigh number for the case of a dimensionless hole diameter of 0.10 .

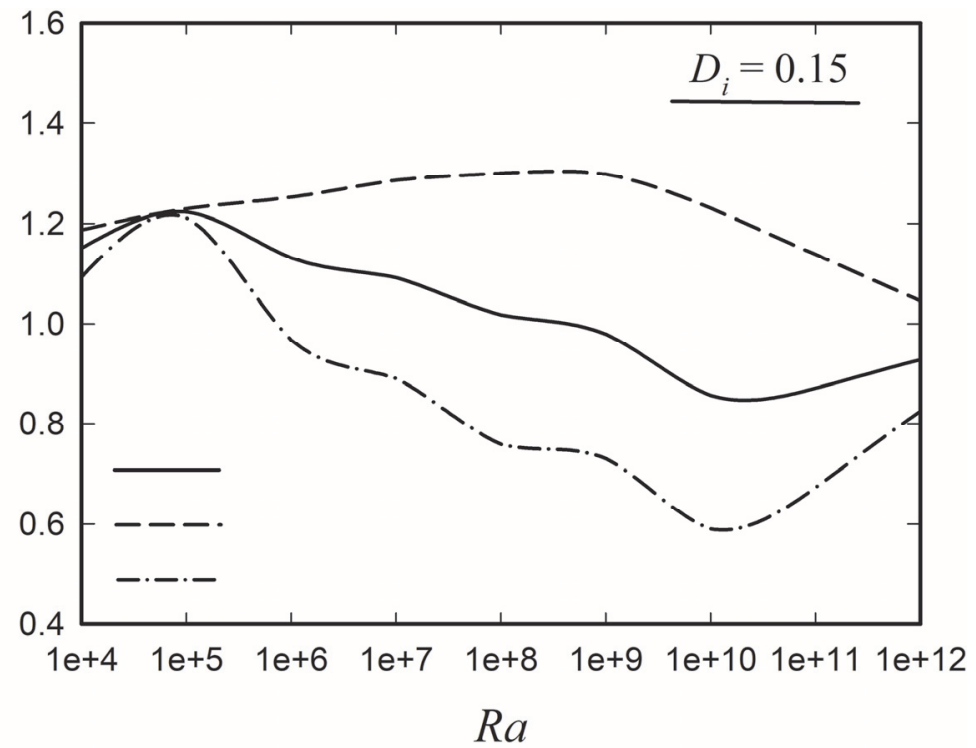

Fig. 15 Variations of the ratios of the total mean Nusselt number, the bottom surface mean Nusselt number, and the top surface mean Nusselt number to the values of the corresponding Nusselt numbers that exist under the same conditions without a hole in the plate with Rayleigh number for the case of a dimensionless hole diameter of 0.15 .

The significant changes in the values of the Nusselt numbers with changes in the Rayleigh number and in the dimensionless hole-diameter values result from the variations in the flow patterns that arise with changes in the values of these parameters. These flow pattern variations are illustrated by the results given in Figs. 16 and 17 . 
TFEC-2020-32193
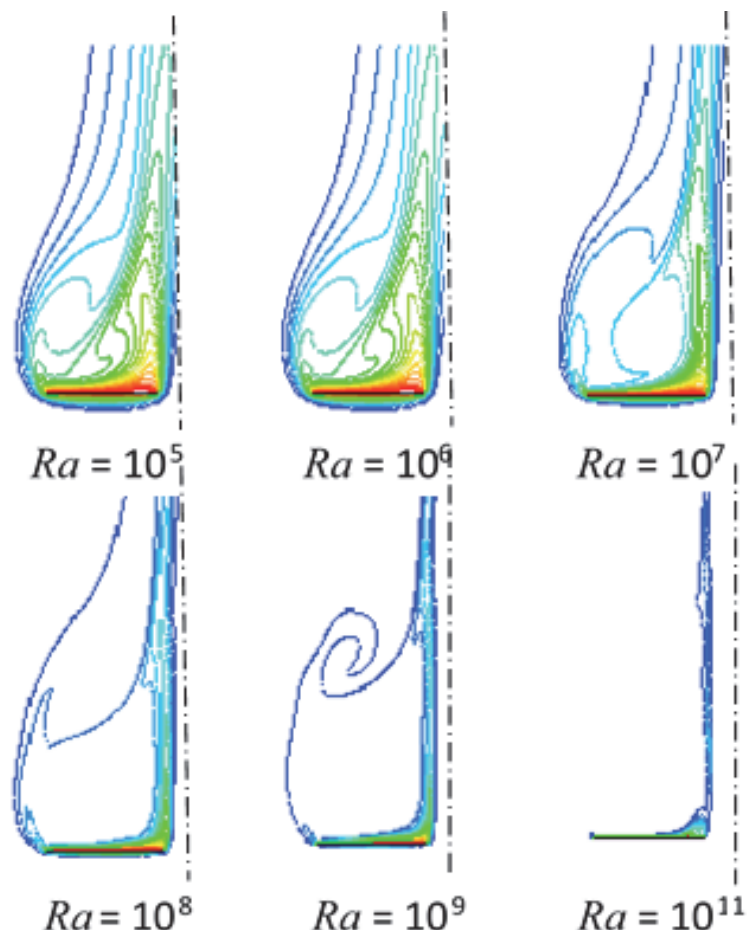

$\operatorname{Ra}=10^{8}$

$$
R a=10^{9}
$$$$
R a=10^{11}
$$

$$
D_{i}=0.2
$$

Fig. 16 Typical dimensionless temperature contours for various values of Rayleigh number for the case of a dimensionless hole diameter of 0.2 .
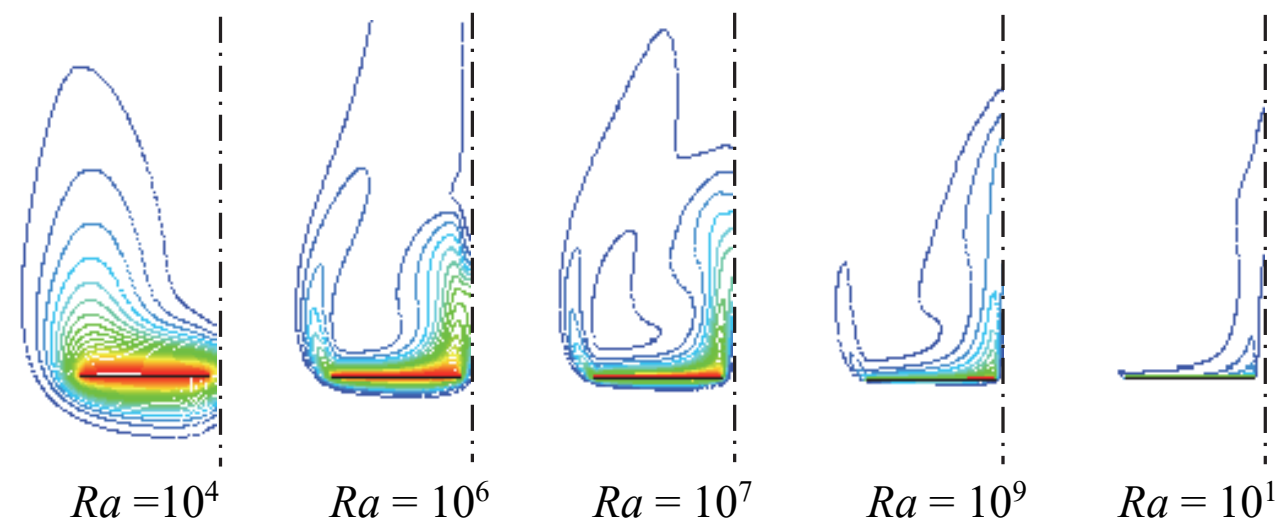

$$
D_{i}=0.05
$$

Fig. 17 Typical dimensionless temperature contours for various values of Rayleigh number for the case of a dimensionless hole diameter of 0.05 . 
These two figures show typical dimensionless temperature contour values, the dimensionless temperature being defined by:

$$
\theta=\frac{T-T_{f}}{T_{w}-T_{f}}
$$

The contour values thus vary from 1 at the plate surfaces to zero far from the plate. Figure 16 shows typical contours for various Rayleigh number values for a dimensionless hole diameter of 0.2 while Fig. 17 shows typical contours for various Rayleigh number values for a dimensionless hole diameter of 0.05 . It will be noted from these figures that there is a strong upward flow over the outer edge of the plate and through the center hole at the lower Rayleigh number values considered whereas the upward flow is dominantly though the center hole at the higher Rayleigh number values considered.

The use of a reference length scale to allow the correlation of the mean total Nusselt number-Rayleigh number variations for different dimensionless hole diameters will next be considered. It has often been assumed (e.g., see [14], [20] and [35]) that, for natural convective heat transfer from horizontal heated elements of various shapes, if a reference heated surface size, $l$, defined by:

$$
l=4 \frac{A}{P}
$$

is introduced ( $A$ is the area of the top and bottom surfaces of the plate and $P$ is the total perimeter of the bottom plus the top surfaces) and if Nusselt and Rayleigh numbers based on this mean reference size are used, then the variations of Nusselt number with Rayleigh number for various element shapes will be the same. This has been investigated for the flow situation here being considered, i.e., for the case of a circular plate that in general has a circular center hole. Taking into account the upper and lower surface areas and the upper and lower perimeters:

$$
l=4 \frac{2 \times(\pi / 4)\left[d_{o}^{2}-d_{i}^{2}\right]}{2 \times \pi\left(d_{o}+d_{i}\right)}=\left(d_{o}-d_{i}\right), \text { i.e, } \quad L=\left(D_{o}-D_{i}\right)
$$

where $L=l / d_{n}$, Nusselt and Rayleigh numbers based on $l$ are then introduced, these being defined by:

$$
N u_{l}=N u\left(\frac{l}{d_{n}}\right) \text {,i.e., } N u_{l}=N u L \text { and } R a_{l}=R a\left(\frac{l}{d_{n}}\right)^{3} \text {,i.e., } R a_{l}=R a L^{3}
$$

The variations of the mean total Nusselt number based on $l$ with Rayleigh number based on $l$ for different dimensionless hole diameters are shown in Fig. 18 and it will be seen that the results for the different hole diameters do effectively fall on a single curve. 


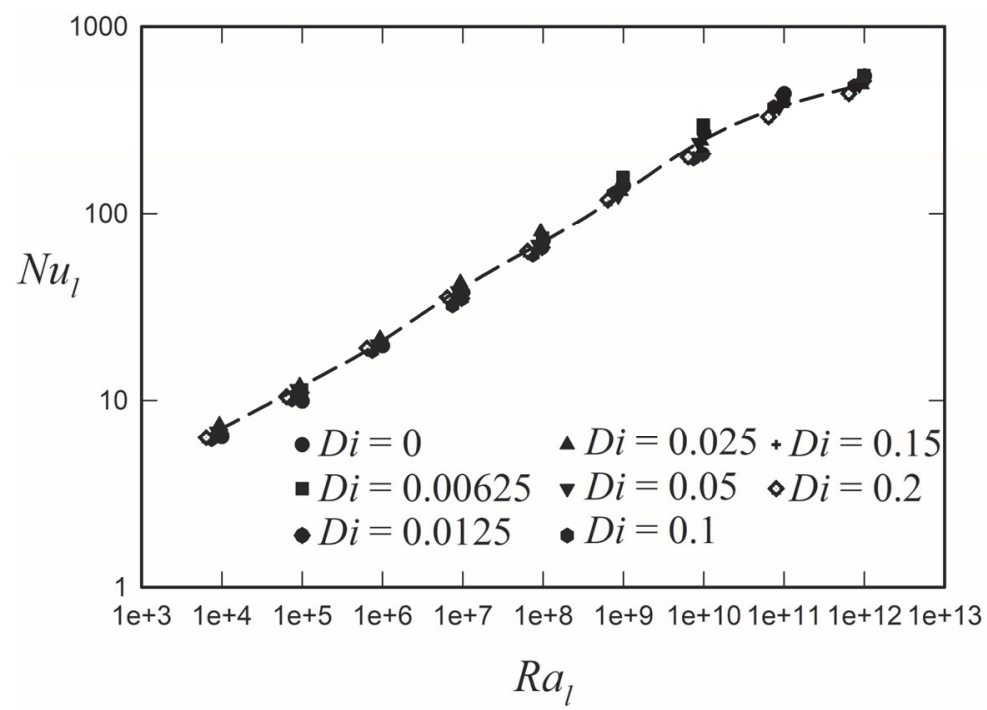

Fig. 18 Variation total mean Nusselt number base on $L$ with Rayleigh number based on $L$ for various values of the dimensionless hole diameter.

\section{CONCLUSIONS}

The results obtained in the present study show that:

1. The presence of a center hole in a plate can, under some conditions, increase the heat transfer relative to that which would exist under the same conditions for a plate without a center hole. However, the presence of a center hole can, under other conditions, decrease the heat transfer relative to that which would exist under the same conditions for a plate without a center hole.

2. Under essentially all conditions, the heat transfer rate from the bottom surface of the plate is greater than that from the top surface of the plate. In essentially all cases, the presence of the center hole increases the heat transfer rate from the bottom surface of the plate and decreases the heat transfer rate from the top surface of the plate.

3. The presence of the center hole produces significant changes in the flow pattern over the plate, the changes also being strongly influenced by the Rayleigh number.

4. If Rayleigh and mean Nusselt numbers for the entire surface, $R_{a l}$ and $N_{u l}$, based on a reference size, $l$, are used then the variations of $N_{u l}$ with $R_{a l}$ are essentially the same for all values of $D_{i}$ considered.

\section{ACKNOWLEDGMENT}

This work was supported by the Natural Sciences and Engineering Research Council of Canada (NSERC) through its Discovery Grant Program (RGPIN-06444-2015).

\section{NOMENCLATURE}

$\begin{array}{llllll}A & \text { total area of heated surfaces of plate } & \left(\mathrm{m}^{2}\right) & d_{n} & \text { diameter of plate without a center hole } & (\mathrm{m}) \\ D_{o} & \text { dimensionless outside diameter of plate } & & d_{i} & \text { diameter of center hole in plate } & (\mathrm{m}) \\ & \left(=d_{o} / d_{n}\right) & (-) & d_{o} & \text { diameter of plate with center hole } & (\mathrm{m}) \\ D_{i} & \text { dimensionless diameter of center hole } & & g & \text { gravitational acceleration } & \left(\mathrm{m} / \mathrm{s}^{2}\right) \\ & \text { in plate }\left(=d_{i} / d_{n}\right) & (-) & L & \text { dimensionless reference length }\left(=l / d_{n}\right) & (-)\end{array}$


$l \quad$ reference length

$\mathrm{Nu}$ mean Nusselt number based on $d_{n}$ for heat transfer from all heated surfaces of plate

$N u_{b o t}$ mean Nusselt number based on $d_{n}$ for heat transfer from bottom surface of plate

$N u_{\text {top }}$ Mean Nusselt number based on $d_{n}$ for heat transfer from top surface of plate

$N u_{0} \quad$ Mean Nusselt number based on $d_{n}$ for heat transfer from all heated surfaces of plate with no center hole

$N u_{b o t 0}$ Mean Nusselt number based on $d_{n}$ for heat transfer from bottom surface of plate with no center hole

$N u_{\text {topo }}$ Mean Nusselt number based on $d_{n}$ for heat transfer from top surface of plate with no center hole

$N u_{l}$ Mean Nusselt number based on reference length $l$ for heat transfer from all heated surfaces of plate (m)

$P \quad$ Total perimeter length of plate

(m)

$P r \quad$ Prandtl number

$(-)$

$(-)$

$q_{b o t}^{\prime}$

mean heat transfer rate from

bottom surface

$q_{\text {mean }}^{\prime}$ mean heat transfer rate for

( - ) both surfaces

$q_{\text {top }}^{\prime} \quad$ mean heat transfer rate from

$\left(\mathrm{W} / \mathrm{m}^{2}\right)$

$\left(\mathrm{W} / \mathrm{m}^{2}\right)$

top surface

( - ) $\quad R a \quad$ Rayleigh number based on $d_{n}$

$\left(\mathrm{W} / \mathrm{m}^{2}\right)$

$(-)$

$R a_{l} \quad$ Rayleigh number based on

reference length $l$

$(-)$

( - ) $T$ temperature

$(\mathrm{K})$

$T_{f} \quad$ fluid temperature far from heated plate

$T_{w} \quad$ temperature of surface of heated plate

$\alpha$

thermal diffusivity

$\left(\mathrm{m}^{2} / \mathrm{s}\right)$

( - ) $\quad \beta$

bulk coefficient of thermal expansion $(1 / \mathrm{K})$

$v$

kinematic viscosity

$\left(\mathrm{m}^{2} / \mathrm{s}\right)$

$\theta \quad$ dimensionless temperature $\left(T-T_{f} / T_{w}-T_{f}\right) \quad(-)$

\section{REFERENCES}

[1] Chambers, B., Lee, T., "A Numerical study of local and average natural convection Nusselt numbers for simultaneous convection above and below a uniformly heated horizontal thin plate," Journal of Heat Transfer, 119, pp. 102-108, (1997).

[2] Wei, J.J., Yu, B., Wang, H.S., Tao, W.Q., 2002, "Numerical study of simultaneous natural convection heat transfer from both surfaces of a uniformly heated thin plate with arbitrary inclination," Int. Journal of Heat and Mass Transfer, 38(4-5), pp. 309317, (2002).

[3] Wei, J.J., Yu, B., Kawaguchi, Y., "Simultaneous natural-convection heat transfer above and below an isothermal horizontal thin plate," Numerical Heat Transfer; Part A: Applications, 44(1), pp. 39-58, (2003).

[4] Corcione, M., Habib, E., Campo, A., "Natural convection from inclined plates to gases and liquids when both sides are uniformly heated at the same temperature," Int. Journal of Thermal Sciences, 50, pp. 1405-1416, (2011).

[5] Fontana. L., "Free convection heat transfer from an isothermal horizontal thin strip: The influence of the Prandtl number," Journal of Thermal Science, 23(6), pp. 586-592, (2014).

[6] Kobus, C.J., Wedekind, G.L., "An experimental investigation into natural convection heat transfer from horizontal isothermal circular disks," Int. Journal of Heat and Mass Transfer, 44, pp. 3381-3384, (2001).

[7] Kobus, C.J., Wedekind, G.L., "An empirical correlation for natural convection heat transfer from thin isothermal circular disks at arbitrary angles of inclination," Int. Journal of Heat and Mass Transfer, 45, pp. 1159-1163, (2002).

[8] Kobus, C.J., Wedekind, G.L., 1995, “An experimental investigation into forced. natural and combined convective heat transfer from stationary isothermal circular disks," Int. Journal of Heat and Mass Transfer, 38(18), pp. 3329-339, (1995).

[9] Oosthuizen, P.H., and Kalendar, A., "A Numerical Study of the Simultaneous Natural Convective Heat Transfer from the Upper and Lower Surfaces of a Thin Isothermal Horizontal Circular Plate," Proc. of ASME 2016 Int. Mechanical Engg. Congress and Exposition, Paper IMECE2016-65540, (2016).

[10] Manna, R. and Oosthuizen, P.H., “ A Numerical Study of Natural Convective Heat Transfer from Two-Sided Circular and Square Heated Horizontal Isothermal Plates having a Finite Thickness," Proc. of $2^{\text {nd }}$ Thermal and Fluid Engg. Conf. and $4^{\text {th }}$ Int. Workshop on Heat Transfer, Paper TFEC-2018-21540, (2018).

[11] Patrick H. Oosthuizen, "Natural Convective Heat Transfer from Two Thin Vertically Spaced Axially Aligned Horizontal Isothermal Circular Plates," Proc. of $2^{\text {nd }}$ Thermal and Fluid Engg. Conf. and $4^{\text {th }}$ Int. Workshop on Heat Transfer, Paper TFECIWHT2017-17451, (2017).

[12] Manna, R. and Oosthuizen, P.H., "A Numerical Study of the Simultaneous Natural Convective Heat Transfer from the Upper and Lower Surfaces of a Thin Isothermal Diagonally Inclined Square Plate," Proc. of $26^{\text {th }}$ Annual Conference of the Computational Fluid Dynamics Society of Canada, Paper MS-322, (2018).

[13] del Rio Oliveira, S. and Oosthuizen, P.H., A Numerical Study of the Simultaneous Natural Convective Heat Transfer from the Top and Bottom Surfaces of a Thin Two-Sided Horizontal Plate Having a Wavy Surface," Proc. of $26^{\text {th }}$ Annual Conference of the Computational Fluid Dynamics Society of Canada, Paper MS-224, (2018). 
[14] Manna, R. and Oosthuizen, P.H., "Natural Convective Heat Transfer from Two-Sided Heated Horizontal Isothermal Plates Having a Complex Shape and a Finite Thickness," Int. Heat Transfer Conf., vol. 16, pp. 3025-3032, (2018).

[15] Oosthuizen, P.H., "Natural Convective Heat Transfer from a Horizontal Rectangular Isothermal Element Imbedded in a Plane Adiabatic Surface with a Parallel Adiabatic Covering Surface," Proc. of ASME 2014 Int. Mechanical. Engg. Congress and Exposition, Paper IMECE2014-36780, (2014).

[16] Oosthuizen, P.H., "Natural Convective Heat Transfer from a Horizontal Isothermal Circular Element Imbedded in a Flat Adiabatic Surface with a Parallel Adiabatic Covering Surface," Proc. of AIAA/ASME Joint Thermophysics and Heat Transfer Conf., Paper AIAA-2014-3357, (2014).

[17] Oosthuizen, P.H., "A Numerical Study of Natural Convective Heat Transfer from a Horizontal Isothermal Square Element Imbedded in an Adiabatic Surface with a Parallel Adiabatic Covering Surface," Proc. of $10^{\text {th }}$ Int. Conf. on Heat Transfer, Fluid Mechanics and Thermodynamics. Paper 1569876763, (2014).

[18] Oosthuizen P.H., "Natural Convective Heat Transfer from an Inclined Isothermal Square Flat Element Mounted in a Flat Adiabatic Surrounding Surface," Proc. of. $15^{\text {th }}$ Int. Heat Transfer Conf., Paper IHTC15-8499, (2014).

[19] Oosthuizen, P.H., "Laminar and Turbulent Natural Convective Heat Transfer from a Horizontal Rectangular Isothermal Element Imbedded in a Flat Adiabatic Surrounding Surface," Proc. of. $6^{\text {th }}$ Int. Symposium on Advances in Computational Heat Transfer (CHT-15), Paper CHT-15-145, (2015).

[20] Oosthuizen, P.H., "A Numerical Study of Natural Convective Heat Transfer from Horizontal Isothermal Heated Elements of Complex Shape," Proc. of. $1^{\text {st }}$ Thermal and Fluids Engg. Summer Conf. (ASTFE), Paper TFESC-12863, (2015).

[21] Oosthuizen, P.H., "A Numerical Study of Natural Convective Heat Transfer from a Horizontal Isothermal Square Element with an Unheated Square Adiabatic Inner Section," Proc. of $10^{\text {th }}$ Int. Conf. on Heat Transfer, Fluid Mechanics and Thermodynamics. Paper 570075655, (2015).

[22] Oosthuizen, P.H., "A Numerical Study of Natural Convective Heat Transfer from a Pair of Adjacent Horizontal Isothermal Square Elements Embedded in an Adiabatic Surface-Effect of Element Spacing on Heat Transfer Rate," Proc. of 10 th Int. Conf. on Heat Transfer, Fluid Mechanics and Thermodynamics, Paper 1570075659, (2015).

[23] Oosthuizen, P.H., "A Numerical Study of Natural Convective Heat Transfer from a Horizontal Isothermal Surface with Rectangular Surface Roughness Elements," Proc. of $1^{\text {st }}$. Pacific Rim Thermal Engg. Conf., Paper PRTEC-14630, (2016).

[24] Oosthuizen, P.H., "Natural Convective Heat Transfer from a Heated Upward Facing Recessed Isothermal Horizontal TwoDimensional Element with and without Heated Side Walls," Proc. of $25^{\text {th }}$ Annual Conf. of the Computational Fluid Dynamics Society of Canada, Paper CFD2017-317, (2017).

[25] Oosthuizen, P.H., "A Study of the Effect of Triangular and Rectangular Surface Waves on the Natural Convective Heat Transfer from A Circular Upward Facing Heated Horizontal Isothermal Surface," Proc. of $13^{\text {th }}$ Int. Conf. on Heat Transfer, Fluid Mechanics and Thermodynamics, Paper 1570340040, (2017).

[26] Oosthuizen, P.H., and Kalendar, A.Y., "Natural Convective Heat Transfer from Upward Facing Recessed and Protruding Heated Horizontal Isothermal Circular Elements with Isothermal Vertical Side Surfaces," Proc. of $13^{\text {th }}$ Int. Conf. on Heat Transfer, Fluid Mechanics and Thermodynamics, Paper 1570340039, (2017).

[27] Oosthuizen, P.H., "A Numerical Study of the Effect of Adiabatic Side Sections on Natural Convective Heat Transfer from a Downward Facing Heated Horizontal Isothermal Surface," Proc. of $25^{\text {th }}$ Annual Conf. of the Computational Fluid Dynamics Society of Canada, Paper MS-223, (2018).

[28] Savill, A.M., "Evaluating turbulence model predictions of transition. An ERCOFTAC special interest group project," Applied Scientific Research, 51, pp. 555-562, (1993)

[29] Schmidt, R.C., Patankar, S.V., "Simulating boundary layer transition with low-Reynolds-number $k-\varepsilon$ turbulence models: Part 1-an evaluation of prediction characteristics," Journal of Turbomachinery, 113, pp. 10-17, (1991)

[30] Plumb, O.A., Kennedy, L.A., "Application of a $k$-e turbulence model to natural convection from a vertical isothermal surface," Journal of Heat Transfer, 99, pp. 79-85, (1977).

[31] Zheng, X., Liu, C., Liu, F., Yang, C.-I., "Turbulent transition simulation using the k- $\omega$ model," Int. Journal for Numerical Methods in Engineering, 42(5), pp. 907-926, (1988).

[32] Albets-Chico, X., Oliva, A., Perez-Segarra, C.D., "Numerical experiments in turbulent natural convection using two-equation eddy-viscosity models," Journal of Heat Transfer, 130(7), pp. 072501-1-072401-11, (2008).

[33] Oosthuizen, P.H., and Naylor, D., "A Numerical Study of Laminar-to-Turbulent Transition in the Flow Over a Simple Recessed Window-Plane Blind System," Proc. of $4^{\text {th }}$ Canadian Solar Buildings Conf., Toronto, M. Stylianou, ed., The Solar Buildings Research Network, Montreal, (2009).

[34] Xamán, J., Álvarez, G., Lira, L., Estrada, C., "Numerical study of heat transfer by laminar and turbulent natural convection in tall cavities of façade elements," Energy and Buildings, 37(7), pp. 787-794, (2005).

[35] Hassani, A.V., and Hollands, K.G.T., 1987, "A Simplified Model for Estimating Natural Convection Heat Transfer from Bodies of Arbitrary Shape," Proc. of ASME 24th National Heat Transfer Conf., (1987). 